\author{
П. Б. Арясов ${ }^{1}$, С. Ю. Нечаев ${ }^{1}$, \\ А. В. Дмитриенко을 С. Н. Константиненко² \\ ${ }^{\dagger}$ Научно-исследовательский институт \\ радиационной защиты АТН Украины

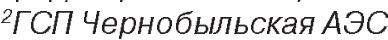

\section{Программа мониторинга} радиоактивных

\section{аэрозолей}

\section{с применением}

\section{персональных}

\section{импакторов}

\section{при выполнении работ на объекте «Укрытие»}

Представлена структура разработанной и внедренной специальной программы мониторинга радиоактивных аэрозолей с применением персональных пробоотборников аэрозолей (ППА) и персональных импакторов (ППАИ), позволяющей получить полный наборданных относительно характеристик радиоактивных аэрозолей в зоне дыхания персонала в зависимости от разных типов выполняемых работ.

\section{П. Б Арясов, С. Ю Нечаєв, О. В Дмитриєнко,}

С. М. Константиненко

Програма моніторінгу радіоактивних аерозолів із застосуванням персональних імпакторів при виконанні робіт на об'єкті «Укриття»

Наведено структуру розробленоїта впровадженої спеціальної програми моніторінгу радіоактивних аерозолів із застосуванням персональних пробовідбірників аерозолів (ППА) та персональних імпакторів (ППАИ), яка дає змогуотримати повний набір даних щодо характеристик радіоактивних аерозолів у зоні дихання персоналу в залежності від різних типів виконуваних робіт.

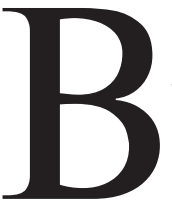

течение 2004-2008 гг. в рамках Плана осуществления мероприятий (ПОМ) на объекте «Укрытие» (ОУ) выполнены работы по стабилизации нестабильных конструкций ОУ (так называемая фаза стабилизации). Большинство из указанных работ внутри ОУ связано с повышенным образованием радиоактивных аэрозолей, поскольку проводится в радиоактивно загрязненных помещениях, где радиационная обстановка сложилась, преимущественно, в результате аварии 1986 г. В соответствии с требованиями Норм радиационной безопасности [1], при осуществлении практической деятельности для контроля доз внутреннего облучения персонала регламентируется только один путь поступления - ингаляционный. Основными факторами, формирующими дозу внутреннего облучения, являются дисперсный и радионуклидный состав, а также тип системного поступления радиоактивных аэрозолей [2], [3]. Фактически, в зависимости от реальных значений упомянутых параметров радиоактивных аэрозолей, значения коэффициентов доза на единицу поступления могут отличаться на порядок по сравнению со значениями, рекомендованными МКРЗ для референтных параметров радиоактивных аэрозолей [1]. Таким образом, наличие реальных, натурных данных, которые характеризуют радиоактивные аэрозоли, играет первостепенное значение для дальнейшей корректной интерпретации данных мониторинга производственной среды для выполнения дозовых оценок. Это положение закреплено нормативными документами Украины [1], в соответствии с требованиями которых для дальнейшей интерпретации, выполнения дозиметрических оценок, расчета доз внутреннего облучения персонала предпочтение отдается натурным первичным данным, характеризующим радиационную обстановку на рабочем месте. По сравнению с интегральными характеристиками радиоактивных аэрозолей на рабочем месте, данные о характеристиках радиоактивных аэрозолей непосредственно в зоне дыхания персонала имеют приоритетное значение для дальнейших дозиметрических интерпретационных процедур [3].

Для получения наиболее ценных дозиметрических данных - натурных характеристик радиоактивных аэрозолей непосредственно в зоне дыхания персонала - была поставлена задача разработки и внедрения специальной программы мониторинга радиоактивных аэрозолей с применением персональных пробоотборников аэрозолей (ППА) и персональных пробоотборников аэрозолей импакторного типа (ППАИ персональных импакторов). До внедрения и реализации данной программы мониторинга каких-либо аналогов с применением ППАИ в Украине не существовало. Реализация данной программы мониторинга на практике позволяет получить полный набор реальных данных относительно характеристик радиоактивных аэрозолей в зоне дыхания персонала в зависимости от разных типов выполняемых работ.

В соответствии с поставленной задачей разработана структура специальной программы (рис. 1) мониторинга радиоактивных аэрозолей с применением персональных импакторов [5], которая имеет четыре основных направления:

подготовительные и организационные процедуры; экспериментальная часть;

радиометрические измерения;

контроль качества.

Фактически каждое из перечисленных направлений является самостоятельным и обладает своей субструктурой. Первые три направления имеют иерархическое подчинение, а процедуры контроля качества относятся к каждому элементу программы, связывая все части воедино. 
Контроль качества

Маркировка
Хранспортировка
Хранение
Калибровка
Дезактивация
Контроль
Двойные измерения
"Бланковые" пробы

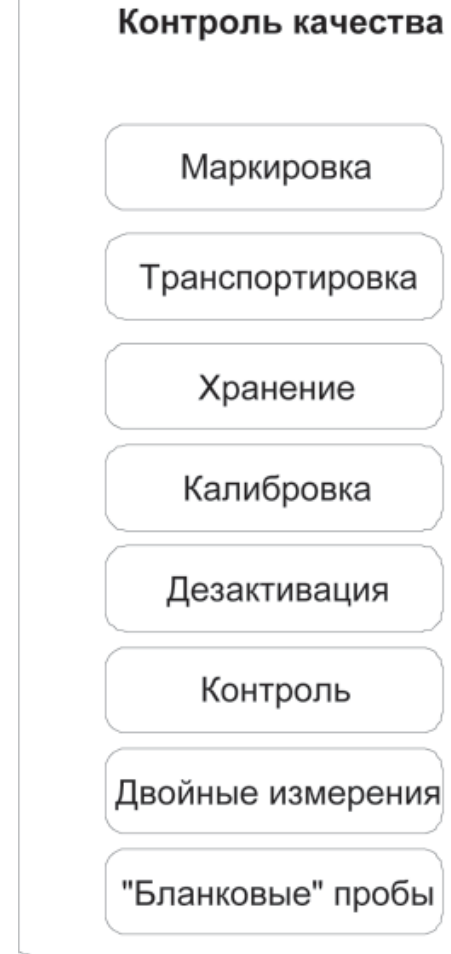

\section{Подготовительные и организационные процедуры}
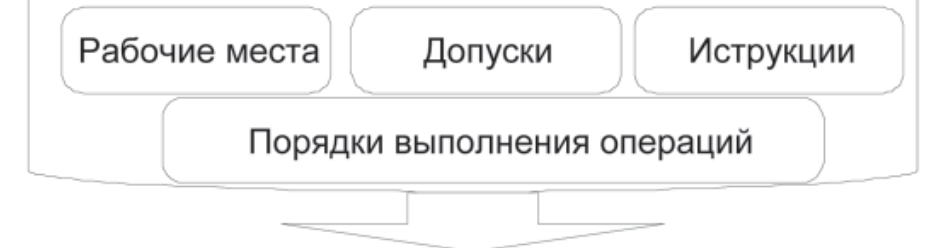

\section{Эксперимент}

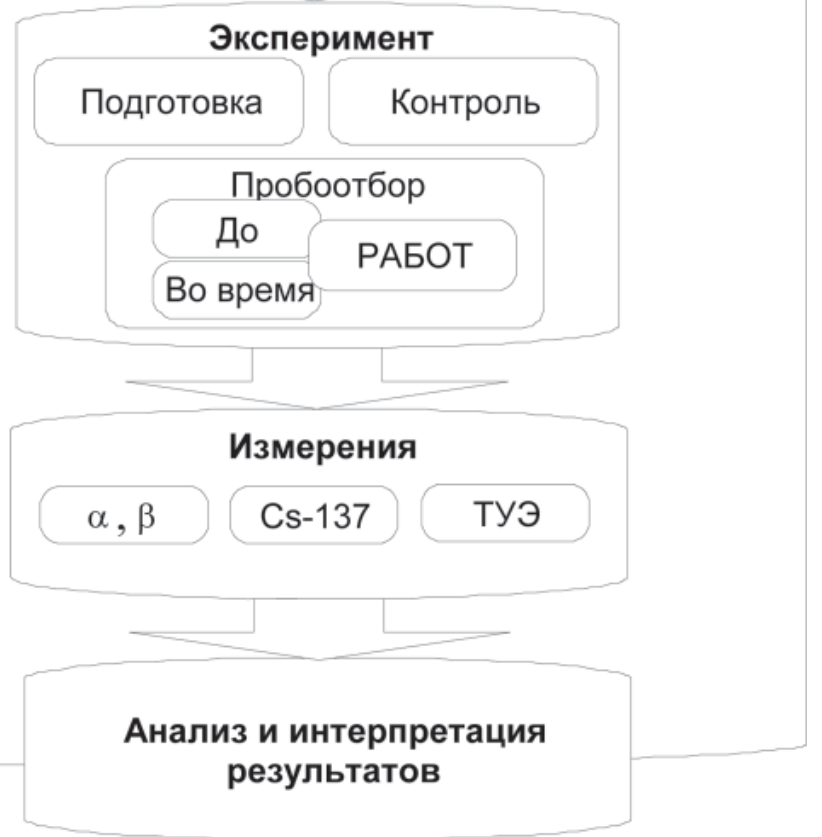

Рис. 1. Структура специальной программы мониторинга радиоактивных аэрозолей

\section{Оборудование}

При реализации программы мониторинга с применением персональных импакторов в качестве основного оборудования были использованы персональные каскадные импакторы «Marple» [4] серии 290 двух типов: шестикаскадные импакторы МР-296 и восьмикаскадные МР-298. Модель МР-298 отличается от МР-296 наличием двух дополнительных каскадов для разделения крупнодисперсных аэрозолей. Данные каскады имеют маркировку «1» и «2». Уровни отсечки по каскадам в зависимости от аэродинамического диаметра аэрозолей для используемых импакторов приведены в табл. 1 .

Таблица 1. Уровни отсечки по каскадам для персональных каскадных импакторов «Marple» серии 290 при скорости прокачки 2 л·мин ${ }^{-1}$

\begin{tabular}{|c|c|c|}
\hline Номер каскада & $\begin{array}{c}\text { Уровень отсечки, } \\
\text { мкм }\end{array}$ & Модель \\
\hline 1 & 21,3 & MP-298 \\
\hline 2 & 14,8 & MP-298 \\
\hline 3 & 9,8 & MP-298, MP-296 \\
\hline 4 & 6 & MP-298, MP-296 \\
\hline 5 & 3,5 & MP-298, MP-296 \\
\hline 6 & 1,55 & MP-298, MP-296 \\
\hline 7 & 0,93 & MP-298, MP-296 \\
\hline 8 & 0,52 & MP-298, MP-296 \\
\hline Финальный фильтр & 0 & MP-298, MP-296 \\
\hline
\end{tabular}

Как видно из табл. 1, указанное оборудование позволяет получить максимально полную информацию о дисперсном составе радиоактивных аэрозолей во всем диапазоне ингалибельной фракции. При проведении экспериментов в качестве подложек и финального фильтра использовались два вида фильтрующих материалов: стекловолоконные фильтры типа GF-230SEC (для каскадов) и GF-230SEF (для финального фильтра), а также целлюлозные фильтры типа WH. Для стандартных ППА были использованы стекловолоконные фильтры GF.

Для предотвращения эффекта «отскока» частиц от фильтруюших материалов применялась силиконовая смазка «Loctite 8021» (силиконовый спрей). Смазка наносилась тонким слоем на поверхность фильтрующих материалов каскадов импактора в лабораторных условиях. После нанесения смазки фильтры выдерживались до полного ее высыхания для последующей зарядки в импакторную головку.

Для персональных импакторов использовались помпы двух типов: «Gil Air-5» и «Gilian 3500», позволяющие удерживать постоянную скорость прокачивания воздуха от 1 до 5 л.мин ${ }^{-1}$ и до 3,5 л мин ${ }^{-1}$ соответственно. При проведении экспериментов скорость прокачки была установлена на уровне рекомендуемой руководством по эксплуатации [4] и составляла 2 л мин ${ }^{-1}$.

Для калибровки помп и установки необходимого уровня скорости прокачки применялись два калибратора «Gilian» модели «Gilibrator-2» с насадками «Gilian» (генератор пузырей), работающие на мыльном растворе.

Наряду с персональными импакторами, в реализации программы также были задействованы персональные 
пробоотборники аэрозолей (ППА) стандартного типа (не импакторные). Для ППА использовались помпы SKS с установленной скоростью прокачки воздуха 4 л·мин ${ }^{-1}$.

\section{Подготовительные \\ и организационные процедуры}

Данную часть программы можно условно разделить на три основных направления:

1) проверка работоспособности, метрологическая поддержка;

2) организация и подготовка рабочих мест (для работы с оборудованием);

3) организационные работы, связанные с проведением экспериментов.

Проверка работоспособности, метрологическая поддерж$\kappa a$. Все персональные импакторы и воздушные помпы, используемые в программе, до начала ее реализации прошли метрологическую аттестацию и поверку, подвергнуты проверке на стабильность и длительность работы все комплекты оборудования. При полном заряде аккумуляторных батарей воздушных помп, путем проверки на калибраторе скорости прокачки в начале отбора и по истечении 5 ч (в конце пробоотбора), отклонений от начальной скорости прокачки обнаружено не было. Аналогично, опытным путем установлено, что время непрерывной работы всех воздушных помп при полностью заряженной батарее составляет не менее 8 ч. Согласно указанной выше схеме, проверки проводились регулярно в течение выполнения программы мониторинга, с периодичностью 1,5-2 мес. Метрологическая аттестация всего оборудования в ходе выполнения программы проводилась согласно предварительно составленному плану.

Организационная структура проведения экспериментов предусматривала в первую очередь исключение внешнего загрязнения фильтрующих материалов, вероятность чего в условиях ОУ очень высока. Для исключения возможного внешнего загрязнения образцов были организованы рабочие места в радиационно-чистых помещениях.

Первое из них расположено в лабораторных условиях вне ОУ и предназначено для следующих работ с персональными импакторами:

разборки импакторов;

упаковки фильтров;

дезактивации импакторов;

маркировки фильтров;

сборки импакторов.

Таблица 2. Паспорт на воздушную пробу персонального импактора

\begin{tabular}{|l|l|}
\hline Дата & \\
\hline $\begin{array}{l}\text { Код - идентификатор операции } \\
\text { (по результатам рассмотрения ППР) }\end{array}$ & \\
\hline Единый наряд-допуск (ЕНД) & \\
\hline Организация (исполнитель) & \\
\hline Фамилия, имя, отчество (полностью) & \\
\hline Номер помешения/место работы & \\
\hline Выполняемые работы & \\
\hline Время начала работы & \\
\hline Продолжительность работы & \\
\hline $\begin{array}{l}\text { Серийный номер импактора } \\
\text { (не заполняется для стандартных ППА) }\end{array}$ & \\
\hline Серийный номер воздушной помпы & \\
\hline Примечания/ремарки & \\
\hline
\end{tabular}

Второе рабочее место находится непосредственно на 4-м блоке ЧАЭС, где выполняюся следующие операции:

выдача персональных импакторов при допуске работников к работам;

прием персональных импакторов по завершении работ; оформление технических паспортов воздушных проб; дезактивация воздушных помп и шлангов;

калибровка воздушных помп;

зарядка аккумуляторных батарей воздушных помп.

Организационные работы, связанные с проведением экспериментов, включали в себя комплекс задач - от оформления официальных разрешений до разработки инструкций выполнения операций с оборудованием. Для четкой и корректной работы были разработаны инструкции по обращению с воздушными помпами типов Gil Air-5, Gilian 3500, SKS, а также «Порядок выдачи ППА, ППИА», регламентирующий работы, которые должны проводиться в обязательном порядке с использованием персональных импакторов и/или ППА.

Для соблюдения целостности и полноты сопровождающей информации по завершении работы заполнялся специально разработанный паспорт на воздушную пробу, форма которого представлена в табл. 2.

\section{Контроль качества}

С целью обеспечения достоверности и надежности получаемых в рамках программы результатов был разработан ряд процедур, направленных на обеспечение контроля качества выполняемой программы в целом (данная часть касается всех составляющих программы).

Маркировка, транспортировка, хранение фильтрующих материалов. Согласно разработанному порядку обращения с фильтрами персональных импакторов, чистые фильтры с обратной стороны маркировались мягким простым карандашом (табл. 3) для дальнейшей сборки импактора.

В случае, когда фильтры персональных импакторов подвергались взвешиванию, непосредственно в лабораторных условиях НИИ Р3 сначала проводилась процедура маркировки фильтров, которая несколько отличалась от описанной выше: на каждом фильтре из комплекта импактора, кроме номера фильтра, был нанесен номер комплекта для однозначной идентификации каждого фильтра. После маркировки фильтры выдерживались в течение 24 ч в помещении с постоянной температурой и влажностью и затем взвешивались. Вес каждого фильтра заносился в базу данных, а сами фильтры упаковывались в зип-пакеты и доставлялись в ЦРБ ЧАЭС для последующей зарядки в импактор.

После проведения пробоотборов, при разборке и перезарядке импакторов фильтры складывались «пробой внутрь», упаковывались в зип-пакеты и комплект фильтров одного персонального импактора вместе с паспортом на воздушную пробу скреплялся стиплером.

После доставки серии комплектов фильтров в НИИ Р3 каждый комплект в серии маркировался, все комплекты данной серии помещались в специальный контейнер с ее номером до подготовки к измерениям. Таким образом был сформирован «банк проб» фильтрующих материалов с сохранением всей сопровождающей информации о пробоотборах.

Если фильтры с отобранными воздушными пробами были предварительно взвешены (о чем свидетельствует специальная маркировка фильтров), то они выдерживались в течение 24 ч 
Таблица 3. Порядок маркировки фильтров персональных импакторов

\begin{tabular}{|c|c|c|}
\hline \multirow{2}{*}{ Номер каскада } & \multicolumn{2}{|c|}{ Маркировка фильтра } \\
\cline { 2 - 3 } & Модель МР-298 & Модель MP-296 \\
\hline 1 & 1 & - \\
\hline 2 & 2 & - \\
\hline 3 & 3 & 3 \\
\hline 4 & 4 & 4 \\
\hline 5 & 5 & 5 \\
\hline 6 & 6 & 6 \\
\hline 7 & 7 & 7 \\
\hline 8 & 8 & 8 \\
\hline Финальный фильтр & Ff & Ff \\
\hline
\end{tabular}

при таких же постоянной температуре и влажности, как и при процедуре взвешивания перед пробоотбором, и затем взвешивались. Вес каждого фильтра заносился в базу данных.

После проведения измерений те фильтры (комплекты фильтров), которые на данный момент времени не были подвержены радиохимическому анализу, возвращались в банк проб в соответствующий комплект, в соответствующую серию фильтров.

Калибровка, дезактивация воздушных помп. Работы, связанные с калибровкой и деактивацией воздушных помп, проводились непосредственно на 4-м блоке ЧАЭС, в помещении ЦРБ (рабочее место № 2 на базе ЦРБ).

Калибровка воздушных помп выполнялась с помощью двух калибраторов «Gilian» модели «Gilibrator-2». Каждая воздушная помпа подвергалась процедуре калибровки с последующей установкой скорости прокачки 2 л.мин ${ }^{-1}$ для ППИА и 4 л.мин ${ }^{-1}$ для ППА, каждый раз непосредственно после проведения пробоотбора (перед следующим пробоотбором). Процедура калибровки включает:

1) подготовку к работе калибратора (зарядка батареи, приготовление/заливка мыльного раствора);

2) установку необходимой скорости прокачки на воздушной помпе с помощью встроенного датчика расхода воздуха;

3) подключение воздушной помпы к калибратору и проведение 10 контрольных замеров скорости потока;

4) корректировку (при необходимости) скорости потока воздуха на воздушной помпе с помощью встроенного датчика расхода в соответствии с показанием среднего значения скорости потока на калибраторе;

5) проведение 20 замеров расхода воздуха и определение средней скорости потока;

6) занесение результатов калибровки в результирующую таблицу (табл. 4).

Как показала практика эксплуатации программы, процедура калибровки воздушных помп перед каждым пробоотбором существенно повышает достоверность информации, характеризующей пробоотбор. Дезактивация воздушных помп и шлангов проводилась также непосредственно после проведения пробоотбора и заключалась в протирке салфеткой, смоченной в спирте.

Таблица 4. Форма для занесения результатов калибровки воздушных помп

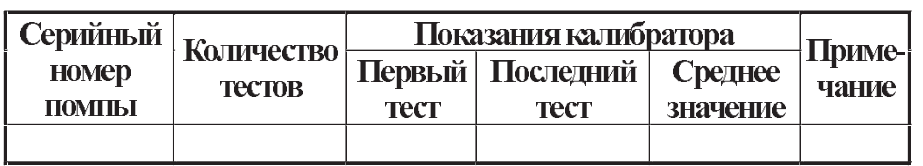

Работы с персональными импакторами: сборка, разборка, дезактивация. После отбора воздушных проб на весь комплект оборудования ППИА, персональные импакторы доставлялись в лабораторию радиоэкологического мониторинга, где и проводись работы по их перезарядке и дезактивации. Технологически процедура перезарядки импакторов состоит из таких операций:

1) последовательной разборки каскадов импактора;

2) складывания подложки/фильтра «пробой внутрь» и упаковки каждого фильтра в отдельный зип-пакет;

3) маркировки каждого пакета номером каскада импактора;

4) разборки следующего каскада импактора и повторения пп. 2 и 3 ;

5) по завершении разборки импактора - проведения дезактивации каждого каскада методом протирки неворсистым материалом, смоченным в спирте, и проверки щелей каскадов на предмет засорения;

6) маркировки чистых фильтров;

7) последовательной сборки каскадов импактора с учетом п. 6.

Все работы с фильтрующими материалами проводились с помощью пинцетов, при полном отстутствии контакта с какими-либо поверхностями.

После проведения четырех пробоотборов (примерно раз в месяц) персональные импакторы подвергались полной дезактивации, состоящей из трех стадий:

предварительной - протирка спиртом всех плоскостей и составляющих, с проверкой/удалением засорений из щелей импакторных каскадов специальным деревянным экстрактором;

основной - полное погружение составляющих частей импактора в ванночки со спиртом на 120 мин;

заключительной - извлечение из ванночек по истечении 120 мин и протирка насухо составляющих персональных импакторов.

Процедуры по обеспечению контроля качества при проведении радиометрических измерений. Для каждого типа измерений (суммарная активность $\alpha$-, $\beta$-излучающих радионуклидов, содержание ${ }^{137} \mathrm{Cs}$, радиохимическое выделение трансурановых элементов - ТУЭ) устанавливался свой идентификатор для каждой пробы, и только после завершения всего комплекса измерительных и радиохимических процедур каждой пробе приписывалось значение по содержанию определяемых радионуклидов. Введение данной процедуры при измерениях позволяет избежать возможности получения «расчетных» результатов и обеспечивает реальные, натурные данные. Наряду с указанной процедурой, периодически (раз в месяц) отдельные пробы направлялись на измерения (неразрушающий анализ) повторно под разными идентификаторами измерений. Отклонение в пределах $5 \%$ полученных результатов «двойных» измерений указывало на надежность проводимых радиометрических процедур. Помимо повторных измерений, с целью обеспечения качества получаемых результатов, на измерения подавались «бланковые» («чистые») фильтрующие материалы, не участвующие в пробоотборе. Для обеспечения робастности данных по дисперсному составу, при работе с импакторными пробами, идентификаторы «внутри» импакторной пробы имели нумерацию «не подряд» с изменяющимся законом. Таким образом, при проведении измерений обеспечивалось определение содержания радионуклидов на каждом каскаде импактора именно для каждого конкретного измерения и полностью исключалась какая-либо подгонка (корректировка) результатов на этапе проведения измерений. 


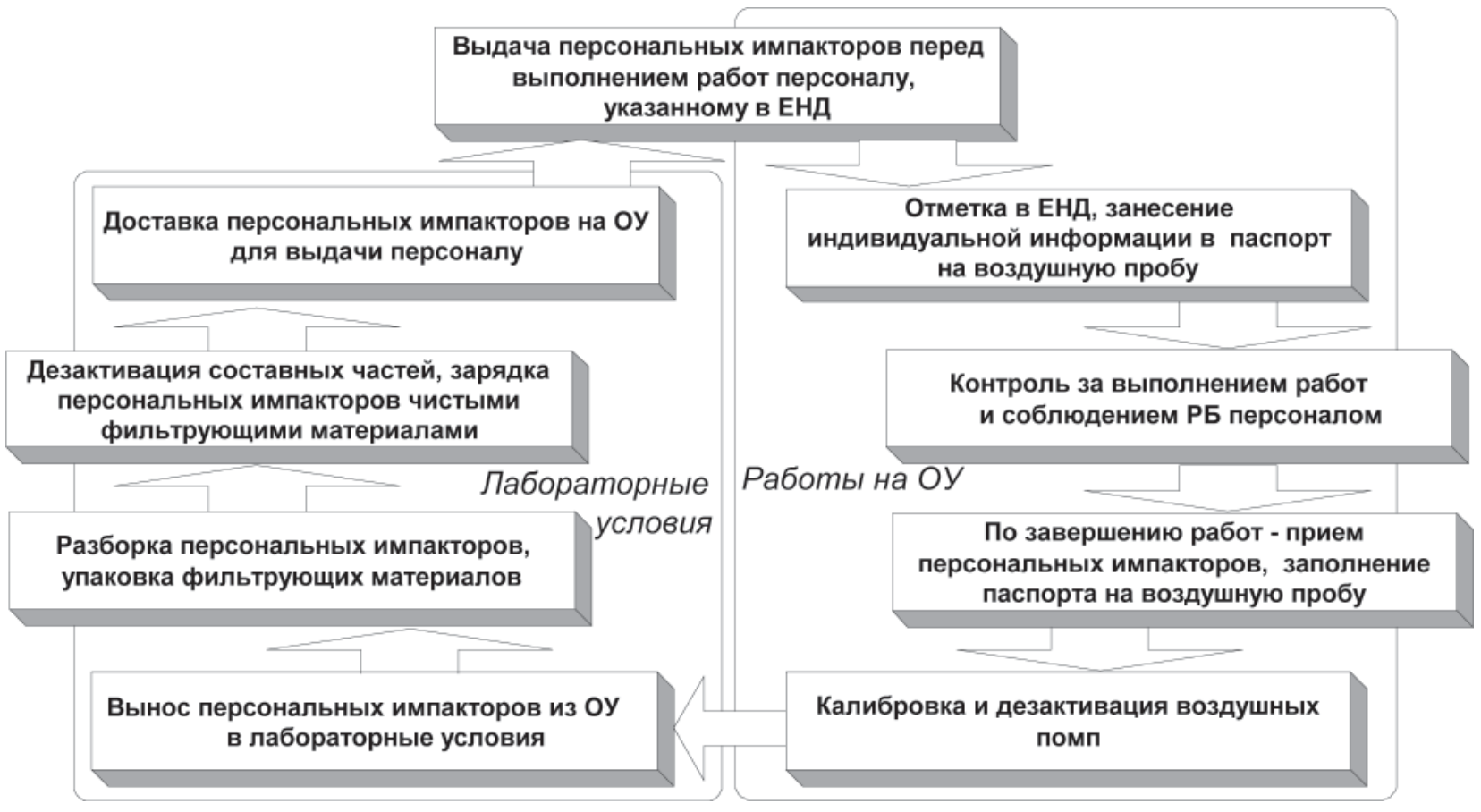

Рис. 2. Детализированная структура экспериментальной части программы с описанием последовательно выполняемых операций

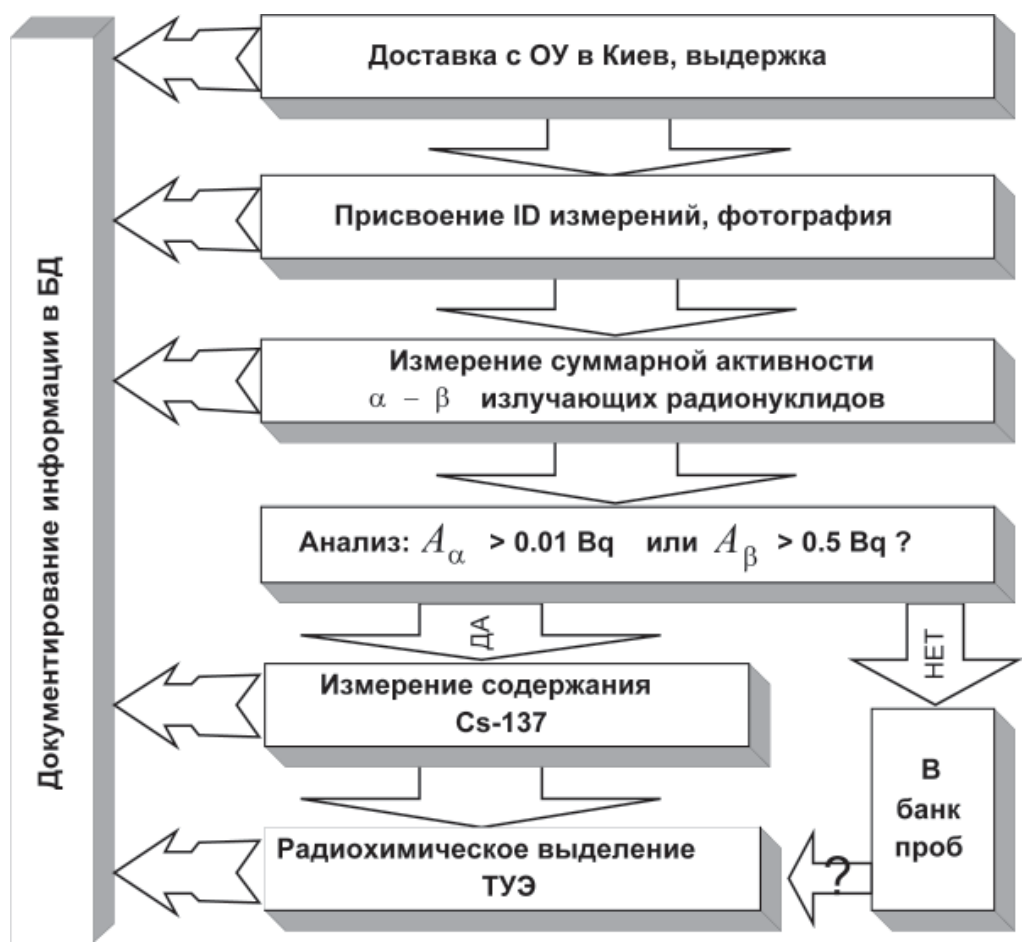

Рис. 3. Схема выполнения операций при проведении спектрометрических и радиометрических процедур 


\section{Экспериментальная часть}

Все работы, планируемые к проведению на ОУ, подвергнуты анализу с точки зрения возможности генерации радиоактивных аэрозолей во время их выполнения; особое внимание обрашено на работы, которые должны осуществляться непосредственно внутри ОУ. По воздействию на окружающую обстановку (предметы) определенных инструментов и устройств выделено пять типов работ; каждому из выделенных типов присвоен классификатор, характеризующий работы, в процессе выполнения которых должен проводиться мониторинг:

Электросварочные работы

Монтажные работы, расчистка зон производства работ

(без сварочных работ и резки металлоконструкций) ............... 2

Работы по подготовке рабочих мест .................................... 3

Работы, связанные со сверлением, бурением, долблением ...... 4

Работы с применением абразивной резки металла .................. 5

Фактически охвачены все радиационно-опасные работы, связанные с повышенной опасностью образования радиоактивных аэрозолей.

При осуществлении программы мониторинга особое внимание было уделено выполнению основных мероприятий по проекту стабилизации ОУ (№№3B, 3С, 14, 14а и усиление западной опоры балки «Мамонт»).

Для реализации экспериментальной части программы мониторинга разработана организационная структура, имеющая четыре основных, последовательно выполняемых составляющих:

1. Изначально все комплекты оборудования (персональные импакторы и воздушные помпы) с неотобранной воздушной пробой находятся непосредственно на ОУ.

2. Выдача и прием персональных импакторов проводится на 4-м блоке ЧАЭС при открытии и закрытии работ в соответствии с инструкциями и «Порядком выдачи ППА, ППАИ».

3. При отборе воздушных проб на весь комплект оборудования ППАИ, импакторы доставляются в лабораторию радиационно-экологического мониторинга ЦРБ ЧАЭС.

4. В тот же день импакторные головки перезаряжаются чистыми фильтрами, дезактивируются и на следующее утро доставляются на 4-й блок ЧАЭС для последующей выдачи (п. 1.).

Детализированная структура экспериментальной части программы с описанием последовательно выполняемых операций представлена на рис. 2

\section{Радиометрические \\ и спектрометрические измерения}

Согласно представленной на рис. 3 схеме, после проведения экспериментов полученные образцы воздушных проб доставлялись сериями с ЧАЭС в лабораторию ИРЗ (г. Киев). Каждая серия выдерживалась 10 дней перед проведением измерений на содержание суммарной активности $\alpha-, \beta$ излучающих радионуклидов. В течение этого времени все комплекты фильтров регистрировались в базе данных с занесением сопутствующей информации из паспортов воздушных проб. Каждому комплекту воздушных фильтров присваивался уникальный идентификационный пятизначный номер «XXX_XX», первые три цифры которого соответствовали номеру серии, а две последние - номеру комплекта.
Непосредственно перед подготовкой к измерениям информация из паспорта на воздушную пробу по каждому комплекту фильтров документировалась с занесением в БД (включая фотографии). На следующем шаге каждый фильтр помещался на мишень, расположенную на подложке с уникальным идентификационным номером ID фильтра; данная комбинация фотографировалась и также заносилась в БД.

После подготовительных процедур все полученные образцы воздушных проб подвергались процедуре измерения суммарной активности $\alpha$-, $\beta$-излучающих радионуклидов. Таким образом для каждой воздушной пробы формировались значения $A_{\alpha}^{\mathrm{ID}}$ и $A_{\beta}^{\mathrm{ID}}$. Эмпирическим путем установлен критерий для дальнейшего проведения измерений на содержание ${ }^{137} \mathrm{Cs}$. Так, если $A_{\alpha}^{\mathrm{ID}}>0,01$ либо $A_{\beta}^{\mathrm{ID}}>0,5$ Бк-пробу ${ }^{-1}$, образцам с указанным ID присваивался новый ID_1 (см. «Процедуры по обеспечению контроля качества при проведении радиометрических измерений») и они подвергались радиометрическому измерению содержания ${ }^{137} \mathrm{Cs}$ в пробе; в результате получали значение $A_{\mathrm{Cs}}$ ID_1. Аналогично предыдущей процедуре, следующим шагом этим образцам присваивался ID «радиохимических измерений» - ID_2 - и они подвергались радиохимическому выделению ${ }^{239+240,238} \mathrm{Pu},{ }^{241} \mathrm{Am}$ с последующими $\alpha$-спектрометрическими измерениями и конечными результатами - значениями $A_{\mathrm{Pu}}{ }^{\mathrm{ID} \_2}, A_{\mathrm{Am}}{ }_{\mathrm{ID} \_2}$. После завершения всех описанных выше процедур и занесения полученных результатов в БД образцы воздушных проб имели матрицу значений $\left[A_{\alpha} A_{\beta} A_{\mathrm{Cs}} A_{\mathrm{Pu}} A_{\mathrm{Am}}\right]$.

\section{Заключение}

Программа мониторинга радиоактивных аэрозолей с применением персональных импакторов и стандартных ППА осуществлялась при выполнении всех радиационноопасных работ по стабилизационным мероприятиям на ОУ. Общее количество полученных и проанализированных образцов воздушной среды за 2005-2008 гг. составило более 4500 (в том числе образцов воздушной среды, отобранных с применением персональных импакторов, -2500$)$, что позволило определить/уточнить основные параметры расчета индивидуальных доз внутреннего облучения персонала.

\section{Литература}

1. Норми радіаційної безпеки України (НРБУ_97). - К.: МОЗ України, 1997. - 121 с.

2. Annals of the ICRP. ICRP Publication 66. Human Respiratory Tract Model for Radiological Protection. - Vienna: Pergamon Press, 1993. - P. 65-80.

3. US DOE, Implementation Guide, G - 10CFR835/C1 - Rev. 1, Internal Dosimetry Program.

4. Instruction Manual. Series 290 Marple Personal Cascade Impactor. $\mathrm{P} / \mathrm{N} 100065-00$.

5. Aerosol monitoring during work inside the "object shelter": Analysis of dispersion and concentration for different work types, Journal of Alloys and Compounds 444-445 (2007) 483-485, Aryasov P., Nechaev S., Tsygankov N., Dmitrienko A.

Надійшла до редакції 16.12.2008. 